\section{IT in Public Libraries: seeking out the user's Perspective.}

\section{Colette Coles}

\begin{abstract}
The Author
Colette Coles is currently a research student at City University's Department of Information

Science. She has also been a Visiting Lecturer at the University of North London since 1994. She has worked for a variety of library and information services, ranging from Amnesty International to the Poetry Library.
\end{abstract}

\begin{abstract}
Explores the results of interviews with 301 public library users regarding users' attitudes to IT and levels of IT literacy. Attitudes averaged 47\% positive, $30 \%$ negative and $23 \%$ neutral. Other views concerned the impact of technology on work, children and quality of life. Library users displayed varying levels of IT literacy. Six types of users were identified: non-users (technophobes); reluctant/anxious; work-related; casual/occasional; experience/regular and high flyers (technophiles). It is essential to understand how public library users perceive IT if electronic sources are to be successfully implemented in public libraries.
\end{abstract}

\section{Acknowledgement}

The research described in this paper is part of a $\mathrm{PhD}$ "Factors affecting the use and non-use of. CDROMs in public libraries: identifying barriers to use" at City University, due for completion at the end of 1998.

\section{INTRODUCTION}

Information Technology in public libraries is a hot topic at the moment. A whole range of research is looking at various aspects of IT in public libraries. There are positive initiatives and messages coming from the new government and there are successful ongoing projects, such as Project Earl, and the take up of the Challenge Fund by public libraries. These are exciting times. Public libraries are redefining their role for the new millennium. Many believe that the future of the Public Library Service is dependent on IT, with a vision of a fully networked Public Library Service. An important aspect, that must not be overlooked in all the excitement, is the user. The user is central to any successful implementation of IT in public libraries. And part of any successful implementation is an understanding of both the user's attitudes to IT and levels of IT literacy. As highlighted in the New Library: People's Network $^{1}$

"...it is important that library users' needs and motivations are understood, and also their perceptions of IT in relation to current library services"

If public libraries are going to provide more and more open access IT facilities, culminating perhaps with the Networked Library, then they must ensure that IT is truly accessible to all current and potential library users. It is important both to find out who the users and non-users of the current IT facilities are and to understand why people use or do not use IT, especially as public libraries have to serve the most diverse range of users. Is it enough to just provide the facilities or do public libraries have a responsibility to make what is inaccessible for some, more accessible? These issues, in particular users' perception of IT services, are currently being examined in a research project at City University ${ }^{2}$. The main focus is to identify barriers to use of open access CD-ROMs in UK public libraries and as such a variety of factors are being looked at, including: environment (library's location, IT facilities) and library user characteristics (demographic profile, IT literacy).

The project has been running since $1995 / 96$, with most of the field work done in 1996/97. The data is being analysed presently and the final results 
are due to be published in 1998.

This article discusses some of the preliminary results from a library user survey, undertaken as part of the research project, concentrating in particular on library users' attitudes to IT and IT literacy levels.

The library user survey consisted of structured interviews with 301 adult library users at 9 selected sites. Quite extensive and detailed information was gathered such as demographic profile, IT background, use and non use of library IT facilities. Both large and small libraries were covered in Suffolk, Essex, Bromley, Croydon, Southwark and City of London (Barbican). Interviews took place in March - May 1997 and included some evening and Saturday morning openings. CD-ROMs were present in every branch, but were much more plentiful in some.

\section{ATTITUDES TO IT}

One section of the interview sought to find out users' attitudes to IT. The aim was to get an idea of what people thought of computer use, how they perceived the impact of IT and whether the impact was seen as positive or negative. Library users' attitude to IT was measured by analysing their responses to the question What impact did they think computers were making on everyday life? This question was very open ended and phrased simply, using the most neutral terms possible. During the pilot study the term 'IT' was used instead of 'computers' but a significant number of people didn't know what IT meant. This very . open-ended question allowed people to express their own thoughts in their own words rather then saying 'yes, no or don't know' to a series of predefined opinions. Whereas this type of opinion gathering is often better done in focus groups, it formed part of an intensive interview in which different information was collected from the user. The main emphasis was to get the most complete picture about the library user.

To a certain extent it was impossible to predict what sort of response users would give. The reactions both to the question itself and users' answers proved interesting and well worth the effort. The question itself caused a variety of reactions. Some respondents were not quite sure what the question meant or more to the point, what answer was required of them. A few users gave some very detailed opinions, as if they had just been thinking about it as they walked into the library. Some were students who broke out into a smile saying

\section{"I'm doing an essay about that very topic"}

Some of these comments were quite well thought out, such as

"The computer is an agent that can provide change, some good, some bad, it depends on uses"

or "...computers are marketed for a select few, they would be more useful if seen as something less frightening, ...could show that older people can use them"

Some responses covered a whole variety of opinions, some at times contradictory. For a very small minority of respondents the question unleashed some very strong emotions. One woman proceeded to discuss her imminent divorce from her husband due to his excessive use of the family PC which she was going to throw out as soon as her divorce came through! Another user, a young woman with a young child, showed signs of computer paranoia believing that computers were very bad for children and were taking over the world. Some replies were very short and straightforward, such as "huge" or "significant" and that was it, the next question please. The conditions for these interviews were not ideal.

Most were in library entrance halls, in noisy, busy areas, with little private space in which to talk, often with no seating so the interview was done standing up; users were often in a hurry and there were 24 questions to get through in about 5-10 minutes!

The responses did however appear to have common themes and it was possible to group them into categories, with some categories divided further by whether the responses on the impact of computers were positive, negative or neutral. 
The main categories were:

- computers were creating changes on particular aspects of everyday life, such as work

- computers were making a huge/significant impact

- computers were a necessary part of everyday life
- computers had specific negative aspects such as "they were over-used" or "they were taking over."

- computers had specific positive aspects such as "they were a useful tool."

Chart I: main attitudes to computers

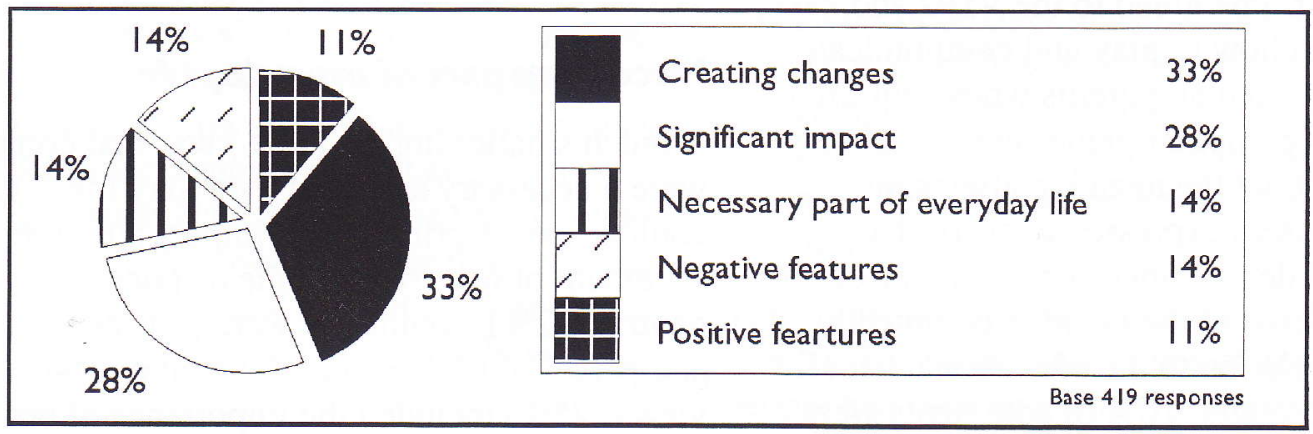

Just under half of all responses expressed positive opinions about the impact of computers while just over a quarter of responses were negative and just under a quarter of the responses were neutral as shown in this chart:

\section{Chart 2: types of responses to use of computers}

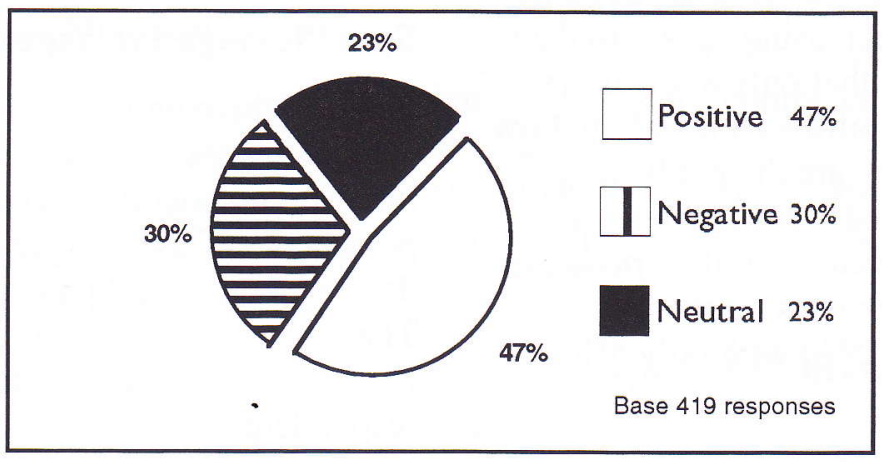

\section{Creating changes}

The largest impact (32\% of responses) was about the changes computers were creating. Users felt that computers were creating changes on either some aspect of everyday life or on particular groups of people. The changes created were either seen as positive $(57 \%)$, as negative $(29 \%)$ or as neutral (14\%). There were five areas in which changes were been perceived as occurring: work, quality of life, children, access to information and communications.

Creating change at work. Users commented on the changes that computers were creating at work. Positive comments (30\%) covered topics such as helping at work. The negative comments
(40\%) were that computers were making people redundant, that work was becoming harder to get as IT skills were needed, computers had deskilled many jobs and skills had changed. Neutral comments, such as that computers had changed the nature of work, accounted for $30 \%$ of comments.

Creating changes in quality of life. Users also commented on the changes computers were making to the quality of life. The views regarding this change were predominately positive (79\%): computers were seen as making life easier, faster, saving time. The few negative comments $(15 \%)$ were that life was changing for comments (15\%) 
were that life was that changing for the worse, too much change was happening too quickly. Only $6 \%$ of comments were neutral.

Change affecting children Another concern of users was the changes computers were having on children. The comments tended to be quite strongly felt. Most of the negative comments (53\%) were about the worry that computer games are either bad for children or that children spend too much of their time glued to the VDU and have perhaps forgotten how to play and communicate with others. In particular, parents whose children were addicted to computer games expressed very strong feelings about the negative affects on children. A few users expressed concern that children's actual development was being affected by computers. Some of the positive comments ( $31 \%$ ) were in relation to the educational benefits that computers brought. $16 \%$ of comments were neutral about the changes computers were making on children.

\section{Creating changes to access to information.}

A few users mentioned that computers were creating changes in access to information. Even though this seemed an obvious change, as IT by its very nature is about increasing access to data, it was perhaps surprising that only a few users mentioned it. Maybe this offers an insight to how information aware or unaware the public are. Only one respondent found that access to information was worse because of the "pedantic" nature of computers. The views were predominantly positive $(95 \%)$ with only $5 \%$ negative.

\section{Creating changes to communications.}

A smaller number of respondents felt that computers had made some impact on communications. The impact was mainly positive (91\%). Communication was thought to be easier with email responsible for most of the improvement. As one user commented "email is opening up the world". But it was not all good news: it was also felt by a very small minority (9\%) that personal communication skills have suffered as a result of computers.

\section{Huge or significant impact}

The second largest impact (28\% of responses) was that computers were making a huge and significant impact on everyday life. Unlike the answers about the changes computers were creating, these responses tended to be very short and simple. Some respondents did elaborate and then described further types of impacts. This impact was seen as either positive $(50 \%)$ or negative $(9 \%)$ or neutral $(41 \%)$.

\section{Necessary part of everyday life}

A much smaller impact (14\%) was that computers were a necessary aspect of everyday life. This couldn't be described as an impact but more a statement of fact. Most of the responses were neutral (52\%), computers were just seen as 'part and parcel of life'. Some of the more positive views $(25 \%)$ included the importance of not getting left behind and of having computer skills. There seemed to be a certain amount of resignation to the presence of computers. Some terms, such as unavoidable, encroaching, inescapable, becoming like TV, expressed a negative viewpoint (23\%).

\section{Specific negative aspects}

Some of the comments (14\%) were about specific negative aspects of computers. What was interesting about these comments was not the percentage of users expressing these views but the degree of emotion that respondents showed.

There were very intense feelings and concerns. Five types of negative aspects were mentioned by respondents:

Over reliance/over use. Users mentioned overreliance as a negative aspect of computer use. It was felt that people had become too reliant on them, that people were becoming lazy and spent too much time using them. Typical comments were that shop assistants were unable to add up unless they used a calculator or that books were being neglected in favour of computers.

Depersonalising. Users also made comments about the depersonalising effects of computers. This was a concern that computers were replacing humans, that the human touch or contact was being lost and with use of computers there was a loss of individualism. 
Taking over. Some users appeared to have paranoid feelings about the impact of computers. These respondents simply felt that computers had too much control and were taking over. Typically these respondents were not very happy to talk about this issue any further. They were obviously uncomfortable about the concept of IT.

Alienating. Users expressed opinions about the alienating effects of computers. Not all respondents necessarily felt alienated themselves but saw computers as alienating for some groups in society, in particular elderly people. Many stressed the frightening effect that computers had. Many of the older respondents felt alienated.

Some other respondents, such as the unemployed or women who hadn't worked since they had had a family, felt excluded and left out because they either didn't have a computer or know how to use one.

Other. A very small number of the comments covered opinions such as hatred of computers, that they wasted paper, invaded privacy.

\section{Specific positive aspects}

Some of the comments (11\%) were about specific positive aspects of computers. Most comments were about the usefulness of computers, something that saves time, is a utensil. These comments were similar to those in the Changing Quality of Life Category but tended to just focus on good aspects of computers. A small number of respondents were computer enthusiasts.

\section{LEVELS OF IT LITERACY}

As well as finding out about library users' IT background, the interview sought to identify library users' level of IT literacy. Defining and measuring IT literacy was not a straightforward task. There are many ways of interpreting IT literacy as well as measuring it, but for the purpose of the project it was decided to keep the criteria quite simple. It was necessary to take into account the interview conditions and the limited scope for going into too much detail. IT literacy was measured by:

- the number of types of IT applications used or not used. The types were: word processors, spreadsheets, databases, games, email,Internet/Web, OPACs and CD-ROMs. Users had the opportunity to give examples of any other types of applications.

- the range of places where IT applications had been used. Responses covered home, work, educational institutions, training centres, libraries, friend/relative's home and cybercafes.

- household ownership of computers, number of computers in user's household was also included.

- levels of anxiety in using computers. Users were asked how they felt about using computers: answers ranged from the very anxious to the very confident. Some users provided alternative options, such as dislike of using computers.

This information gave a basic idea of levels of literacy. By asking what types of application people had used and where they had used them, their level of IT literacy could be established in a very simple and convenient way. The aim was to find out what sort of experience the library users had, the sort of access to computer they had and how they felt about using IT.

The pattern that emerged from the data was a diverse range of IT experiences amongst the respondents - from those who had never knowingly used a computer to those who had used an enormous range of applications in many situations and often had several computers athome. In all 6 levels of IT literacy were identified.

\section{Chart 3: types of IT literacy groups}

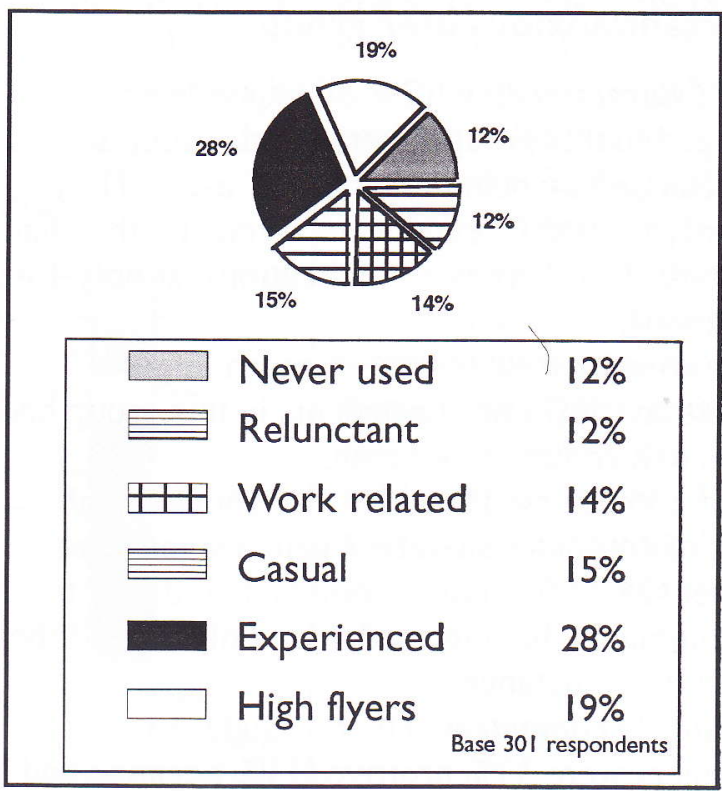


IT in Public Libraries

Colette Coles
Library \& Information Research News (LIRN)

Volume 22 - Number 70 - Spring 1998

\section{Non-user group}

Main Characteristics: $12 \%$ of respondents were classed as non-users. The criteria for this group was simple and straightforward: any respondent with no experience of knowingly using a computer qualified. This group would have been larger as many of the library users approached during the survey, refrained from participating as soon as they found out that some of the questions were about computers. Despite trying to convince them that their opinions were important and that the interview was not a test of their IT expertise, many did not want to do the interview as they thought it would be a waste of time.

Home computer ownership: Only $12 \%$ of respondents had access to a computer at home, as compared to the overall average of the sample of $61 \%$.

Use of computers: Over a quarter of the respondents had absolutely no interest in using IT. However, a small number (11\%) of respondents expressed a desire to use computers. One respondent was a complete contradiction, who said that he felt very confident about using computers and was studying computer science but when asked what IT he had used, he hadn't actually used any, but - he boasted - he knew the theory!

Attitudes to computers: The attitudes to computers that this group exhibited were $41 \%$ negative, $37 \%$ positive and $22 \%$ neutral.

Library CD-ROM usage: None of the respondents had used the library's CD-ROMs (not surprisingly).

\section{Reluctant/anxious user group}

Main Characteristics: $12 \%$ of respondents belonged to this group. Users in this group were characterised by being reluctant IT users. They had only limited IT experience: typically they had used only 1 or 2 types of applications, at only 1 or 2 locations.

Home computer ownership: A much larger proportion (58\%) of respondents in this group had access to a computer at home.

Use of computers: The users also showed high levels of computer anxiety. Again a significant number $(28 \%)$ from this group had no desire to use computers, having used them only a few times with some reluctance.

Attitudes to computers: Their attitudes to computers were $33 \%$ positive, $33 \%$ negative and
$34 \%$ neutral.

Library CD-ROM usage: Only $6 \%$ of respondents from this group had used the library's CD-ROMs.

\section{Work related user group}

Main Characteristics: $14 \%$ of respondents belonged to this category. This group consisted of respondents who had only used IT at work. Home computer ownership: $26 \%$ of the respondents had access to a computer at home but no use was made of them.

Use of computers: Some respondents gave the impression that they did not have any control on whether they used IT or not, it was often something imposed on them at work. Some did see benefits but often IT was seen as something they had to adapt to. $18 \%$ of the respondents from this group expressed either anxiety or reluctance about using computers.

Attitudes to Computers: The attitudes to computers were $39 \%$ positive, $32 \%$ negative and $29 \%$ neutral.

Library CD-ROM usage: None of the respondents from this group had used the library CD-ROMs.

\section{Casual user group}

Main Characteristics: $15 \%$ of respondents belonged to this category. This was an amorphous group covering a diverse range of IT backgrounds but the main features were of low levels of use, such as between 1 to 4 applications used at only one location. The types of users ranged from someone who played computer games but occasionally used a word processor to a college student who used up to 4 applications at college as part of a course.

Home computer ownership: $39 \%$ of respondents had access to a computer at home. A few users tended to use only their home computer.

Use of computers: There were no indications that any respondents were reluctant to use or uninterested in computers.

Attitudes to computers: Attitudes to computers were $41 \%$ positive, $41 \%$ negative and $18 \%$ neutral.

Library CD-ROM usage: Only 5\% of respondents from this group used the library's CD-ROMs.

\section{Experienced user group}

Main Characteristics: This was the largest group with $28 \%$ of respondents belonging to this group. 
Typically the users in this group had used between 5-8 applications at one location only or had used between 2 and 4 types of applications at more than one site.

Home Computer Ownership: There was a high level of home computer ownership (87\%).

Use of computers: There was very little anxiety amongst these respondents. Only $2 \%$ of respondents reported feeling anxious in particular instances such as when using a new or unfamiliar application.

Attitudes to computers: Attitudes to computers were $54 \%$ positive, $28 \%$ negative and $18 \%$ neutral.

Library CD-ROM usage: Only 7\% of respondents from this group used the library's CD-ROMs.

\section{High flyers}

Main Characteristics: This was the second largest group with $19 \%$ of users being classed as high flyers. This group used between 6-8 types of applications at various locations and owned at least one computer but often more.

Home computer ownership: All respondents had access to a computer at home, $17 \%$ of respondents however had access to more than one computer at home.

Use of computers: These respondents were all confident and at ease about using IT.

Attitudes to computers: Attitudes to computers were $61 \%$ positive, $15 \%$ negative and $24 \%$ neutral.

Library CD-ROM usage: This group had the highest usage of library CD-ROM, with $21 \%$ of respondents.

\section{Chart 4: IT literacy groups attitudes to computers}

\section{CONCLUSION}

As expected there is evidence of a wide disparate group of library users. The respondents showed a variety of attitudes about the use of computers. Though overall these views were positive there was still a significant resistance to computers. Many saw the advantages of computers in very general terms (they made life easier). But there were only a small number who saw computers as enhancing access to information and communications. These tended to be people who were high level users of IT. Public libraries have successfully promoted the book and reading since their inception. A continuation of that success must be in the promotion of the benefits of computers, in particular digital information sources and community networks.

Respondents were much more specific about the negative aspects of computers. There was a genuine anxiety for people that they are being left out, left behind. The public library is the only place that could offer them a life line into the information age. Many of the negative impacts are to do with the misuse of computers. The public library is an example of how IT can be put to good use, with good codes of practice. There are some people who will never be won over or converted to IT. Ensuring that they are not denied access to information will be critical. If information is no longer in hard copy and only accessible electronically, access will depend on an intermediary.

The area with the greatest diversity was in the different levels of IT literacy. The highest users of the library CD-ROMs were the High Flyers. Even though these users had a lot of experience and had access to alternative places with IT, they still used public library CDROM services. The public library had successfully attracted maybe the most demanding type of user. But unfortunately the public library did not do too well attracting the less computer experienced users. 
Just providing the hardware and software does not ensure successful take up of the facilities.

Meeting all users needs is a difficult problem to resolve. At one end of the spectrum are the highly information literate users who might desert the public library if the hardware and software are not up to standard. At the other end are library users with little or no IT experience who are anxious about using computers. There is certainly a role for public libraries to target specific groups who have missed out on the Information Revolution, such as the long term unemployed, the elderly and women who stayed at home to bring up a family. These are groups who have not come into contact with IT either at school or at work. It would appear from the survey that most people gained their IT experience either at work or at an educational institution.

The data analysis stage of this research project is at an early stage: we have only just dipped our toe in the water. But already it is clear that the successful implementation of IT in public libraries requires an understanding of users' perception of IT.

\section{REFERENCES}

' Library and Information Commission, New Library: the People's Network, 1997: para 2.I

2 Research is part of a PhD thesis "Factors affecting the use and non-use of open access CD-ROMs in UK public libraries: identifying barriers to use", due for completion end of 1998. For more information contact Colette Coles, Dept of Information Science, City University, email en646@soi.city.ac.uk.. 